\title{
The Voice of the public in Public Health Policy and Planning: the Role of Public Judgement
}

\author{
PATRICIA A. NOLAN
}

N this issue, Scutchfield, Ireson and Hall provide us
with a strong reminder of the importance of willing
participation of the governed in our society. The tools
for participation in improving and maintaining a
community's health that are currently in use are heavThe important changes in policy, law, and services needed to improve health status are in lifestyle, behavior and environment. The ballot box and civic participation is at a low level, especially among those whose health is more precarious. How can the framework of "public judgment" help improve community health?

Looking at the Kentucky example, the process described begins with qualitative data collection. The difference from many current models is that a population survey, in addition to a key informant survey, is used. The community surveyed is invited to view this subjective data and deliberate about its meaning in small forums. As the meaning is decided ("named"), the deliberating forums are encouraged to consider public action, particularly around informing their friends and neighbors about the problems named.

The authors critique several of the currently used models for community participation in public health action, pointing out the heavy reliance on expertise. Engaging the common person is the desired product of all four of the models critiqued. Theory and evidence tell us that changing behavior, environment, policy and/or law, requires buy-in from those who control what is to be changed. A particular risk of the models reviewed is the segmentation of community issues into specialty issues. If using a community deliberation process were 
210 JOURNAL OF PUBLIC HEALTH POLICY • VOL. 25, NO. 2

to lead to more integrated community health actions, it would be a major advance.

There are pitfalls, however. Community participation often follows the naming of a problem, rather than preceding it. Health and public health stakeholders are not the only participants with a tendency to name a problem in narrow or end-driven contexts. Journalists, elected officials, academics, and community advocates share the tendency, but differ on the context. Public hearings are generally used to speak, not to listen. The target audience for the speech is often not even in the room. The challenge is to generate deliberation or civic discourse among those who do not have equal stakes in the outcome.

As an habitué of public hearings, legislative hearings, and stakeholder meetings, I conclude that the skills, the forums and the public support for deliberation are often weak. These authors have provided an interesting conceptual framework for developing deliberation. As they and others conduct similar projects, establishing just what skill sets for facilitators and just what formats for forums are needed to replicate initial successes is important. It is clear from the paper that an active listening component is essential, and that a facilitator needs to guide all participants in this action. Similarly, the survey or polling process needs to be designed to capture the interest of those without an obvious direct stake in the outcomes. The facilitator has to have skills in framing the qualitative and quantitative data to stimulate participation without predetermining the naming of problems.

I look forward to more discussion of the public judgment framework as a tool for developing the skills and the public support for broader community participation in public health policy and program implementation. 